\title{
A PEDOTRANSFER FUNCTION FOR ESTIMATING THE SOIL ERODIBILITY FACTOR IN SICILY
}

\author{
Vincenzo Bagarello, Costanza Di Stefano, Vito Ferro, Giuseppe Giordano, Massimo Iovino
}

\section{Generalities}

The concept of soil erodibility and how to assess it is complicated since the soil susceptibility to erosion is affected by a large number of physical, mechanical, hydrologic and chemical soil properties. Physically based water erosion models use several soil parameters to represent the soil's response during rain and runoff. In contrast, the Universal Soil Loss Equation (USLE) [Wischmeier 1978], with its simplicity, characterizes the soil through a single parameter which can be determined using a series of other, more basic, soil characteristics [Salvador Sanchis 2008]. In particular, the soil erodibility factor, $K$, of the USLE is a simple descriptor of the soil's susceptibility to rill and interrill erosion [Wischmeier 1978]. This factor is defined as the rate of soil loss per erosivity index unity as measured on a standard plot which is $22.1 \mathrm{~m}$ long, has a $9 \%$ slope and is continuously in a clean-tilled fallow condition, with tillage performed up and downslope. The $K$ factor is an integrated long-term average soil response to the erosive power of rainstorms [Römkens 1985] and it represents a lumped factor expressing soil response to many hydrological processes (soil detachment and transport by rainfall and runoff, rainfall infiltration and runoff generation). In Sicily (south Italy), the applicability of the USLE was tested at the experimental station of "Sparacia" during a five year period [Bagarello 2008]. The conclusion was that the model estimated satisfactorily the order of magnitude of the measured mean annual soil loss.

The procedure for determining $K$ needs a knowledge of soil particle size distribution (PSD), soil organic matter, $O M$, content, and soil structure and permeability [Wischmeier 1971]. For increasing spatial scales starting from the plot scale (hillslope, basin, region), the influence of spatial variability of soil properties on erodibility has to be taken into account by carrying out a large number of determinations distrib-

Paper received 26.11.2008; accepted 18.05.2009 uted throughout the area of interest. In this case, reducing the number of input variables in the evaluation procedure of $K$ can be practically attractive for limiting laboratory analyses and, hence, money costs. In particular, excluding $O M$ content from prediction of $K$ may be desirable for work on large scales, given that $O M$ data are often missing in regional soil maps [Zacharias 2007]. Recognizing soil structure and permeability classes may be a bigger challenge than determining $O M$. In practice, developing a method for estimating the soil erodibility factor using only textural data has practical importance, especially in regional analysis.

The soil erodibility factor of the USLE evaluated according to Wischmeier [1971] may be considered as an indirect measure of soil erodibility since several soil properties have to be combined according to a pre-established scheme to deduce $K$. A procedure using limited information to deduce $K$ may be considered as a pedotransfer function (PTF) since an estimate of the property of interest is obtained using a reduced experimental effort.

Attempts to simplify the $K$ evaluation procedure have been carried out in the past and simplified relationships have been proposed for predicting $K$ values of soils for which data are limited (for instance, no information about the very fine sand fraction or organic matter content) [Römkens 1986; Römkens 1997]. Römkens [1986] used data from 249 soils worldwide to propose the following relationship [Verstraeten 2002]:

$K_{R \mathrm{BS}}=0.0035+0.0388 \exp \left[-\frac{1}{2}\left(\frac{\log D_{z}+1.519}{0.7584}\right)^{2}\right]$

where $K_{R 86}\left(\mathrm{t}\right.$ ha h ha-1 $\left.\mathrm{MJ}^{-1} \mathrm{~mm}^{-1}\right)$ denotes the estimate of $K$ deduced by eq.(1) and $D_{g}(\mathrm{~mm})$ is the geometric mean particle diameter.

Römkens [1997], using available global data (225 soils) of measured $K$ values, established mean values of the soil erodibility factor corresponding to soils grouped into different textural classes. The mean value of the soil erodibility factor for each textural class, 
$K_{R 97}\left(\mathrm{t}\right.$ ha h ha ${ }^{-1} \mathrm{MJ}^{-1} \mathrm{~mm}^{-1}$ ), was estimated according to the following relationship [Römkens 1997]:

$K_{\text {R97 }}=0.0034+0.0405 \exp \left[-\frac{1}{2}\left(\frac{\log D_{g}+1.659}{0.7101}\right)^{2}\right]$

Eq.(2), having the same functional form of eq.(1), was included in the RUSLE (Revised USLE) manual [Renard 1997]. To our knowledge, tests of the applicability of eqs.(1) and (2) were not available.

The general objective of this investigation was to develop an estimating procedure of the soil erodibility factor based only on soil textural data for Sicily. At first, the existing relationships were tested using a data-base including 471 values of $K$ determined according to the original procedure suggested in the USLE manual. Subsequently, alternative relationships were developed and tested.

\section{Materials and methods}

Two soil data sets were used for this investigation. The first data set (Sicily data set) includes surface soil samples collected at 243 sampling points uniformly distributed throughout Sicily (Fig. 1) [Giordano 2004]. The second data set (Imera Meridionale basin data set) includes surface soil samples collected at 228 sampling points uniformly distributed throughout the Imera Meridionale basin, having a surface area of $2000 \mathrm{~km}^{2}$ [Ferro 2008].

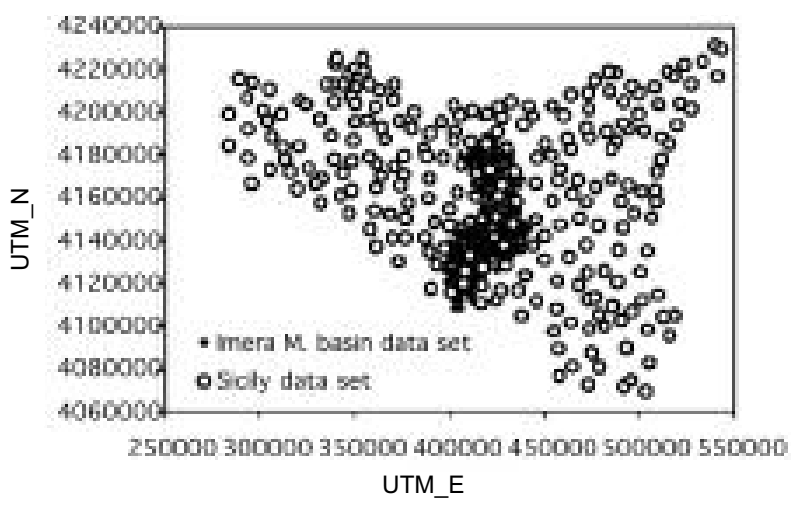

Fig. 1 - Soil sampling points in Sicily and in Imera Meridionale basin.

For each sampling point, the PSD was measured following $\mathrm{H}_{2} \mathrm{O}_{2}$ pretreatment to eliminate organic matter and clay deflocculation by sodium metaphospate and mechanical agitation. Fine size fractions were determined by the hydrometer method, whereas the coarse fractions were obtained by mechanical sieving using mesh sizes of 2000, 860, 425, 250, 106 and $75 \mu \mathrm{m}$. Eight fine fraction data points were obtained by the hydrometer method measuring the suspension density after 2, 5, 15, 30, 60, 180, 1440 and $2880 \mathrm{~min}$. Particle-size fraction data were classified according to the USDA standards [Gee 1986]. For each soil sample, the percentage, $f$, of silt + very fine sand particles $(0.002 \mathrm{~mm}<d<0.1 \mathrm{~mm}$, being $d$ the particle diameter) and the percentage, $g$, of coarse sand $(0.1 \mathrm{~mm}<d<2 \mathrm{~mm})$ were determined using the measured soil particle size distribution. The geometric mean particle diameter, $D_{g}(\mathrm{~mm})$, was also calculated according to the following relationship [Shirazi 1984]:

$$
D_{g}=\exp \left(0.01 \sum_{i=1}^{N} f_{i} \ln m_{j}\right)
$$

where $f_{i}(\%)$ is the primary particle size fraction, $m_{i}$ $(\mathrm{mm})$ is the arithmetic mean of the particle size limits of that size, $i$ is the size fractions number and $N$ is the total number of size fractions. According to Verstraeten [2002], the particle size classes clay, silt and sand $(<0.002,0.002$ to 0.05 , and 0.05 to $2.0 \mathrm{~mm})$ were considered to calculate $D_{g}$. For the size fractions used in this study, values for $m_{i}$ are $0.001,0.026$ and $1.025 \mathrm{~mm}$ for clay, silt and sand, respectively. The total organic carbon content, TOC (\%), was also determined and the organic matter content $(O M)$ was estimated to be equal to 1.724 times the measured TOC value.

For each sample, the structure index, $S S$, was estimated using the available soil texture information and the classification reported in Fig. 2, based on the USDA texture triangle [Giordano 2004].

In particular, the structure index $S S=1$ (very fine granular) was associated to sandy, loamy-sand and sandy-loam soils, $S S=2$ (fine granular) was used for sandy-clay, sandy-clay-loam, loam, silt-loam and silt soils, $S S=3$ (medium or coarse granular) was applied to clay-loam and silty-clay-loam soils, and $S S=4$ (blocky, platy or massive) was used for clay and siltyclay soils. For establishing the permeability index $P P$ of each sampled soil, the classification proposed by

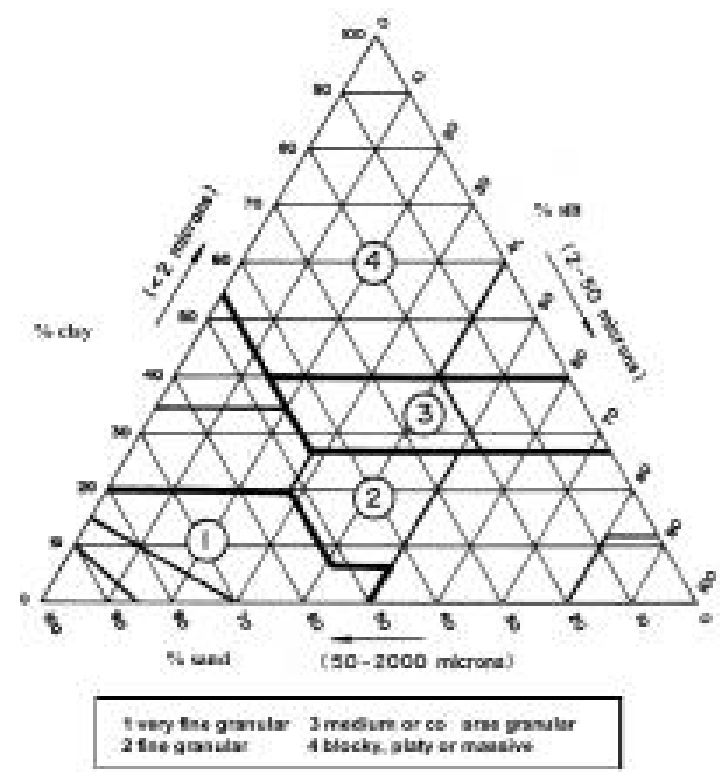

Fig. 2 - Soil structure index, $S S$, classification. 


\begin{tabular}{|c|c|c|}
\hline Soil type & $\mathrm{K}_{\mathrm{s}}\left(\mathrm{cm} \mathrm{s}^{-1}\right)$ & $\mathrm{PP}$ \\
\hline Sandy loam, Loamy sand, Sand & $10^{-3}-10^{-2}$ & 2 \\
\hline $\begin{array}{c}\text { Silt loam, Loam, } \\
\text { Sandy clay loam }\end{array}$ & $10^{-4}-10^{-3}$ & 3 \\
\hline $\begin{array}{c}\text { Clay, Silty clay loam, } \\
\text { Clay loam, } \\
\text { Sandy clay, Silt }\end{array}$ & $10^{-5}-10^{-4}$ & 4 \\
\hline Silty clay & $10^{-6}-10^{-5}$ & 5 \\
\hline
\end{tabular}

TABLE 1 - Proposed ranges of saturated soil hydraulic conductivity, $K_{s}$ [Carsel, Parrish, 1988], and permeability index, $P P$, for the considered groups of soils.

Carsel [1988] for saturated soil hydraulic conductivity $K_{s}$ was used. USDA soil texture classes were grouped according to decreasing values of $K_{s}$.

For each considered textural group, Table 1 lists the expected range of $K_{s}$ values and the corresponding permeability index. Relating both $S S$ and $P P$ to soil texture might induce some criticism since the actual soil structural characteristics are not considered in the determination of $K$. Generally, a soil survey is considered to be enough to estimate structure and permeability categories since the structure and permeability indices can be estimated using qualitative information [Wischmeier 1971]. Soil texture is known to be an important factor controlling soil structure. Therefore, despite the applied procedure being approximate, it is still physically reasonable and objectively repeatable. A similar approach was used in the RUSLE [Römkens 1997].

The applied estimate procedure of $S S$ and $P P$ for the examined soils yielded five values of the product $\operatorname{SSxPP}(2,6,12,16$ and 20).

The soil erodibility factor, $K$ (t ha h ha $\mathrm{MJ}^{-1}$ $\mathrm{mm}^{-1}$ ), and its first approximation, $K^{\prime}$ according to Wischmeier [1971], were calculated by the analytical procedure suggested by Ferro [2006], which gives the same information as the original nomograph. This procedure has the practical advantage of giving an estimate of the soil erodibility factor even if the $O M$ content is higher than $4 \%$.

First, the applicability of eqs.(1) and (2) was tested by comparing $K$ with both $K_{R 86}$ and $K_{R 97}$ for the two data sets. Then, the Sicily data set was used to develop a PTF for estimating $K$ in Sicily. The first approximation, $K^{\prime}$, of the soil erodibility factor was related to the $M$ variable, defined as $M=f(f+g)$ [Wischmeier 1978]. The developed relationship was used to obtain an estimate of $K^{\prime}$, denoted by the symbol $K_{\text {es }}^{\prime}$, and the $K / K_{\text {es }}^{\prime}$ ratio at each sampling point. The mean value of $K / K_{\text {es }}$, was calculated and this mean value was simply multiplied by $K / K_{\text {es }}$ to obtain an estimate of $K$, $K_{e s}$, at a sampling point. A different approach was also applied, taking into account that both $S S$ and $P P$ were related to soil texture.

In particular, the effect of the $S S$ and $P P$ indices on
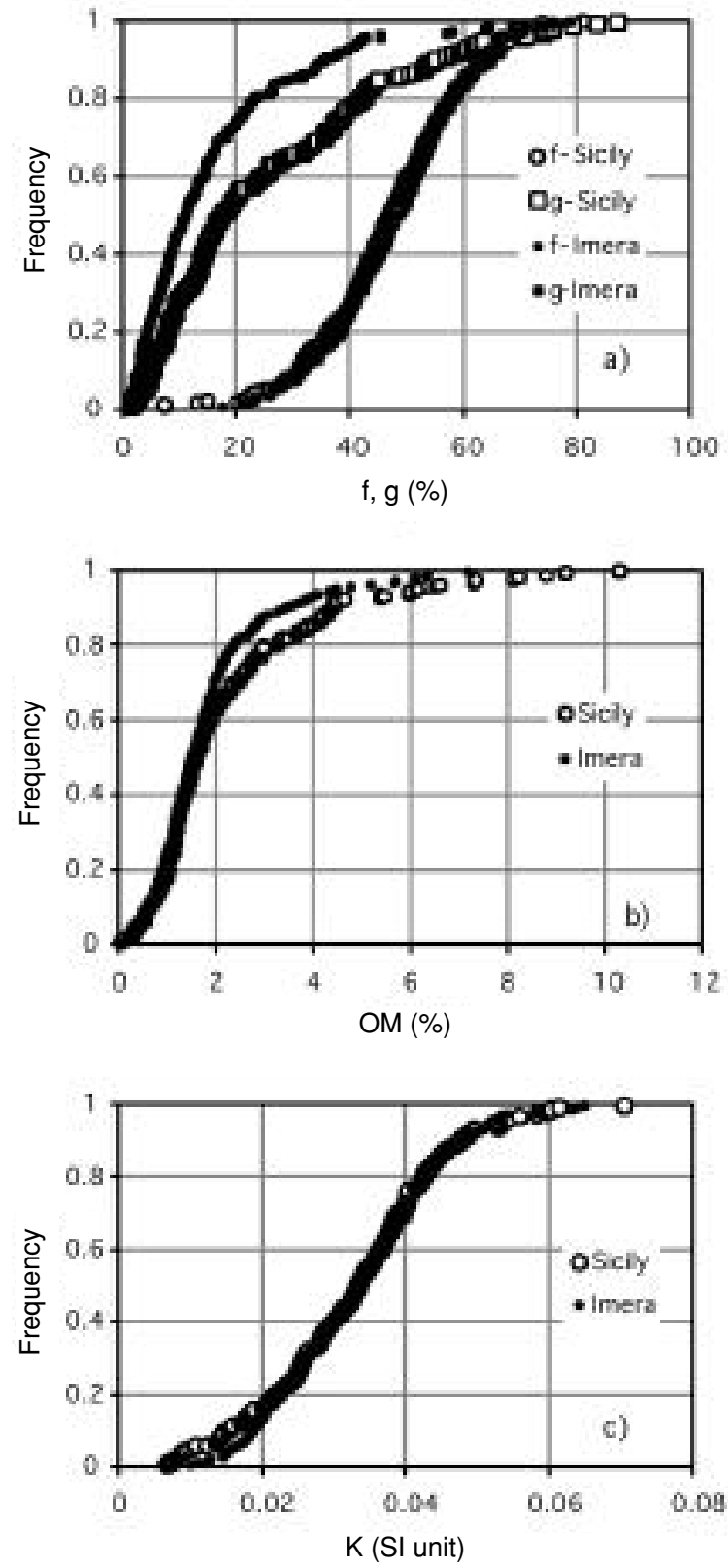

Fig. 3 - Frequency distribution of the variables a) $f$ and $g$, b) $O M$ and c) $K$ for the two considered Sicilian data sets.

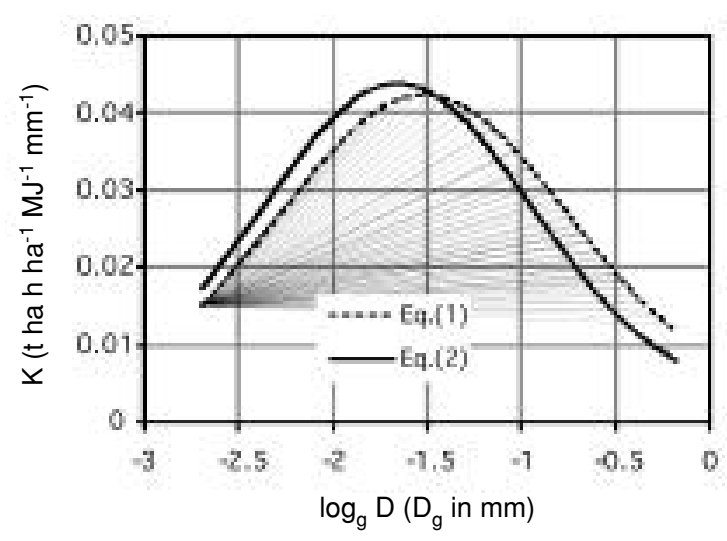

Fig. 4 - Comparison between eqs.(1) and (2). 


\begin{tabular}{|c|c|c|c|c|}
\hline Variable & \multicolumn{4}{|c|}{ Sicily $(N=243)$} \\
\hline & Min & Max & Mean & $\begin{array}{l}\text { Standard } \\
\text { deviation }\end{array}$ \\
\hline$f(\%)$ & 7.5 & 81.3 & 47.8 & 12.6 \\
\hline$g(\%)$ & 1.4 & 87.1 & 25.3 & 19.8 \\
\hline$O M(\%)$ & 0.1 & 10.4 & 2.2 & 1.8 \\
\hline$D_{g}(m m)$ & 0.003 & 0.671 & 0.077 & 0.111 \\
\hline $\begin{array}{c}K \\
\text { (SI units) }\end{array}$ & 0.0069 & 0.0705 & 0.0326 & 0.0123 \\
\hline Variable & \multicolumn{4}{|c|}{ Imera Meridionale basin $(\mathrm{N}=228)$} \\
\hline & Min & $\operatorname{Max}$ & Mean & $\begin{array}{l}\text { Standard } \\
\text { deviation }\end{array}$ \\
\hline$f(\%)$ & 17.7 & 79.1 & 46.8 & 12.2 \\
\hline$g(\%)$ & 0.7 & 75.9 & 15.5 & 14.0 \\
\hline$O M(\%)$ & 0.02 & 7.2 & 1.8 & 1.2 \\
\hline$D_{g}(m m)$ & 0.002 & 0.416 & 0.036 & 0.062 \\
\hline $\begin{array}{c}K \\
\text { (SI units) }\end{array}$ & 0.0101 & 0.0650 & 0.0334 & 0.0112 \\
\hline
\end{tabular}

TABLE 2 - Summary statistics of the measured soil characteristics.

the $K / K^{\prime}$ es ratio was determined and a relationship having the general form of:

$$
K_{e s}=K_{e s}^{\prime} \times f(S S, P P)
$$

was developed. The two procedures were then tested with the Imera Meridionale basin data set.

The performances of all PTFs considered in this investigation were assessed using the residual sum of squares SSE [Ferro 2006] and the Nash-Suttcliffe efficiency index NSEI [Nash 1970]:

$$
\begin{gathered}
S S E=\sum_{i=1}^{N}\left(Y_{m i}-Y_{e s}\right)^{2} \\
N S E I=1-\frac{\sum_{i=1}^{N}\left(Y_{w}-Y_{e s}\right)^{2}}{\sum_{i=1}^{N}\left(Y_{w}-\overline{Y_{w}}\right)^{2}}
\end{gathered}
$$

in which $N$ is the number of the considered data points, $Y_{m}$ and $Y_{e s}$ are the measured and the corresponding estimated values of the considered variable, respectively, and $\overline{Y_{m}}$ is the mean of the measured values. A $N S E I=1$ is indicative of a perfect correspondence between measured and predicted values. A value of NSEI $=0$ suggests that the model predictions are as accurate as the mean of the observed values. A

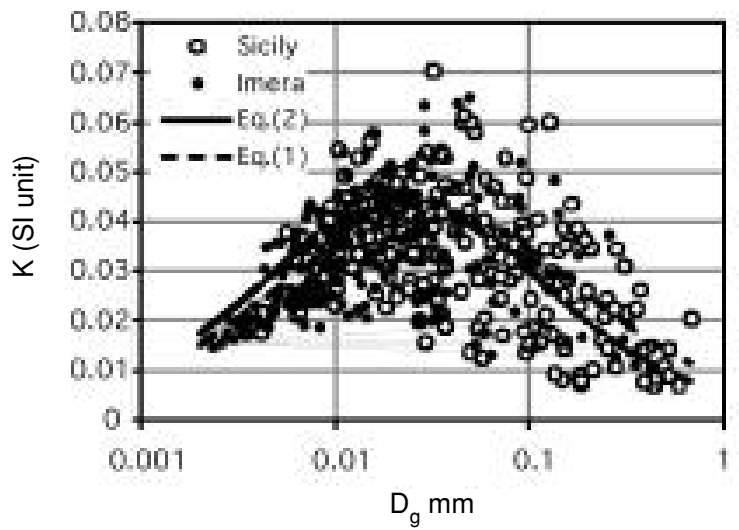

Fig. 5 - Comparison among available Sicilian data points and eqs.(1) and (2).

NSEI value $<0$ suggests that the observed mean is better than the predictions.

A $S S E=0$ is indicative of a perfect correspondence between measured and predicted values.

\section{Results}

For the sampled soils, Fig. 3 shows the empirical frequency distribution of the variables $f, g$ and $O M$. Summary statistics of the measured soil characteristics are reported in Table 2. The soil erodibility factor was calculated for all available soil samples, notwithstanding that in a few cases $O M$ was greater than $4 \%$. Fig. 3 also shows the empirical frequency distribution of the soil erodibility factor (Table 2). The ratio between the maximum and the minimum $K$ factor was equal to 10.3 , suggesting a moderate variability of the soil erodibility factor in Sicily.

Eqs.(1) and (2) have a similar form but they do not coincide (Fig.4). In particular, in the experimental range $0.002<D_{g}<0.67 \mathrm{~mm}$ of this investigation (Table 2), the two equations differ by up to $45 \%$. In addition, the maximum predicted soil erodibility factor $\left(K_{R 86}=0.0423\right.$ for $D_{g}=0.030 \mathrm{~mm}$ and $K_{R 97}=$ 0.0439 for $D_{g}=0.022 \mathrm{~mm}$ ) is appreciably lower than

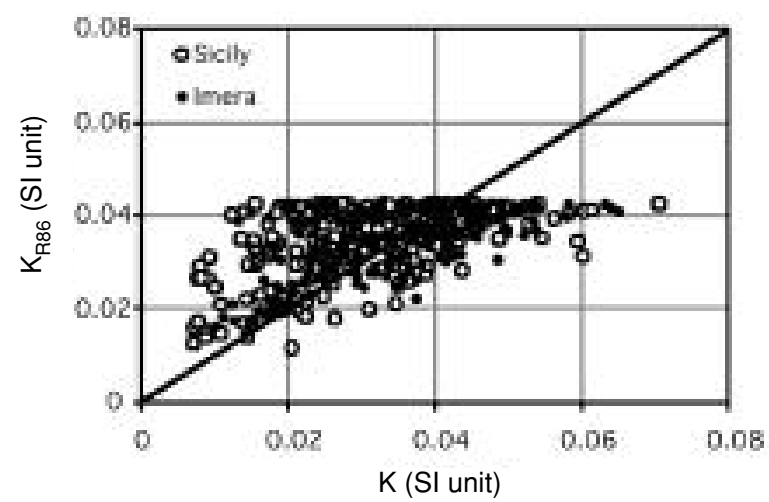

Fig. 6 - Comparison between the soil erodibility factor, $K$, values and the ones estimated by eq.(1), $K_{R 86}$. 


\begin{tabular}{|c|c|c|c|c|c|}
\hline Index & Data-base & Eq.(1) & Eq.(2) & Eq.(9) & Eq.(11) \\
\hline \multirow{3}{*}{ SSE } & Sicily & 0.0265 & 0.0277 & 0.0263 & 0.0118 \\
\cline { 2 - 6 } & $\begin{array}{c}\text { Imera } \\
\text { Meridionale } \\
\text { basin }\end{array}$ & 0.0193 & 0.0226 & 0.0184 & 0.0069 \\
\hline NSEI & Sicily & 0.273 & 0.241 & 0.279 & 0.675 \\
\cline { 2 - 6 } & $\begin{array}{c}\text { Imera } \\
\text { Meridionale } \\
\text { basin }\end{array}$ & 0.320 & 0.206 & 0.354 & 0.756 \\
\hline
\end{tabular}

TABLE 3 - Values of the Nash-Suttcliffe efficiency index, NSEI.

the maximum $K$ value, equal to $0.1 \mathrm{t}$ ha $\mathrm{h} \mathrm{ha}^{-1} \mathrm{MJ}^{-1}$ $\mathrm{mm}^{-1}$, obtainable according to Wischmeier [1971]. Fig. 5 compares eqs.(1) and (2) with the $\left(D_{g}, K\right)$ data pairs of this investigation. Slightly higher NSEI results were obtained with eq.(1) than eq.(2) (Table 3). Eq.(1) is also characterized by a $S S E$ value less than the one corresponding to eq.(2).

The comparison between $K$ and $K_{R 86}$ is shown in Fig. 6. For both equations and both data sets, a noticeable scattering of the data points was detected and rather low values of NSEI $(<0.320)$ were obtained, suggesting that the proposed relationships cannot be used to obtain reliable estimates of the erodibility factor at a selected sampling point. This result was not surprising given that a mean behaviour of the soil erodibility was considered by Römkens [1997]. A possible additional reason was the difference among the different data sets employed by Römkens [1986; 1997] and considered in this investigation.

Both Scheinost [1997] and Bagarello [2007] showed that $D_{g}$ calculations vary with the considered number of particle-size fractions. The same result was obtained in this investigation. As an example for the Imera Meridionale basin data set, Fig. 7 shows the comparison between $D_{g}$ and the corresponding estimate, $D_{g P S D}$, obtained by considering all 14 pairs (diameter, frequency) on the measured PSD curve. A ratio between $D_{g}$ and $D_{g P S D}$ ranging between 1.9 and 5.4 (mean $=2.7)$, depending on the soil sample, was obtained and the two variables were strongly correlated (coefficient of determination, $\mathrm{r}^{2}=0.99$ ) according to the following relationship (Fig. 7):

$$
D_{g P S D}=0.250 \cdot D_{g}^{0.897}
$$

Fig. 7 also shows the following relationship:

$$
D_{g P S D}=0.275 \cdot D_{g}^{0.918}
$$

deduced by Bagarello [2007] in the Ruyigi area (Burundi), using 14 particle size classes to determine $D_{g}$. $P S D$. The two equations are very similar and the lines are practically indistinguishable, suggesting that the experimental area had a practically negligible effect on the relationship between $D_{g}$ and $D_{g P S D}$. Using $D_{g-}$
PSD instead of $D_{g}$ had a noticeable impact on the soil erodibility factor estimated by eq.(2) (Fig. 8). Fig. 9 shows that the relationship between $K^{\prime}$ and $M$ can be expressed by the following power equation:

$$
K_{e s}^{\prime}=6.54 \cdot 10^{-6} M^{1.029}
$$

which is characterized by a coefficient of determination, $r^{2}$, equal to 0.693 .

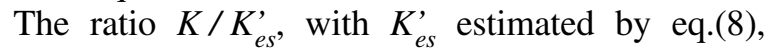
ranged from 0.293 and 2.492 and the mean value of this ratio was equal to 1.186 (coefficient of variation,

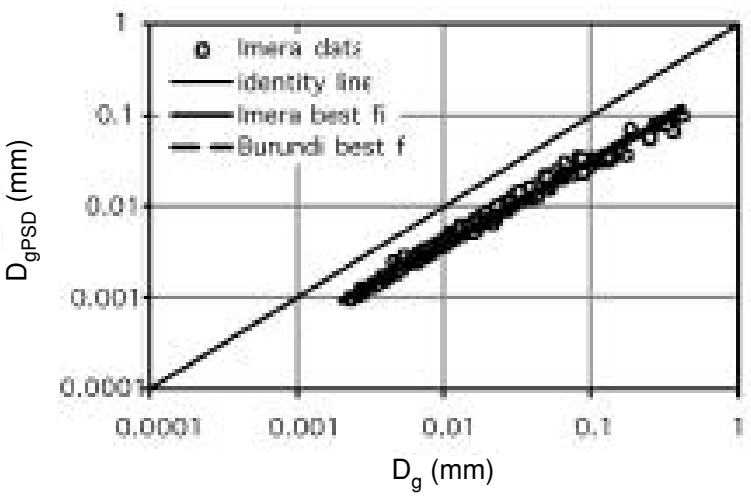

Fig. 7 - Comparison between the geometric mean particle diameter values calculated, according to eq.(3), using the USDA textural classes $\left(D_{g}\right)$ and the ones determined by the measured particle size distribution $\left(D_{g P S D}\right)$.

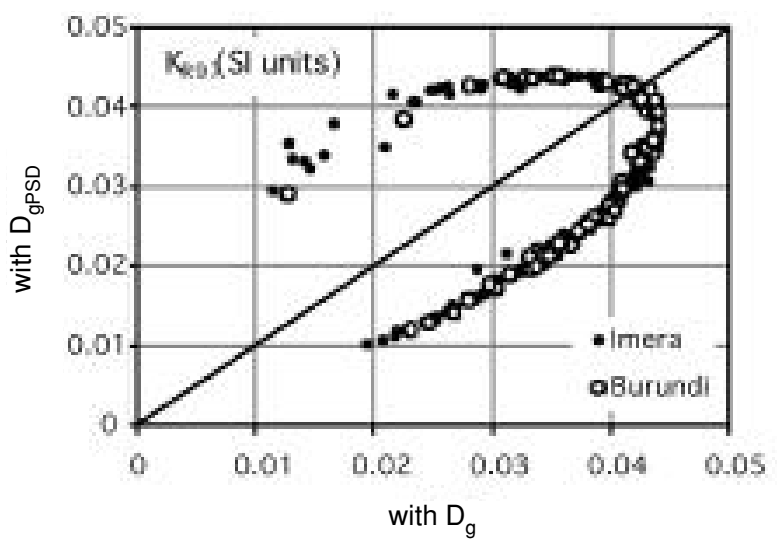

Fig. 8 - Effect of the estimate criterion of the geometric mean particle diameter on the estimated values of the soil erodibility factor.

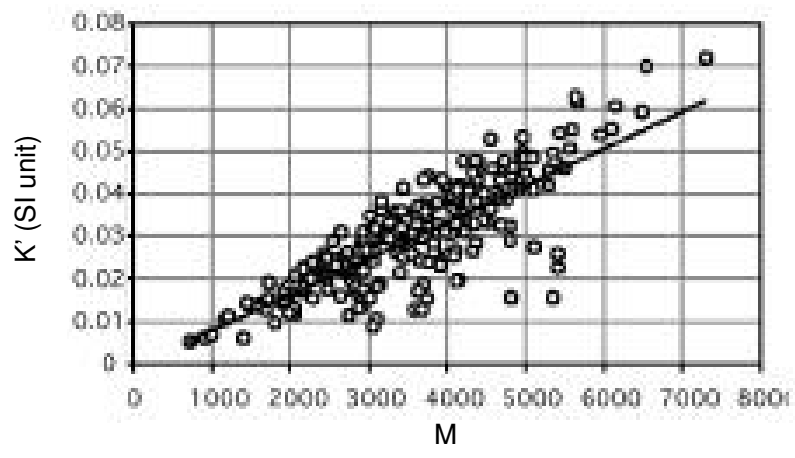

Fig. 9 - Relationship between the first approximation of the soil erodibility factor, $K$, and the $M$ parameter. 
$C V=36 \%$ ). Therefore, an estimate of the soil erodibility factor, $K_{e s}$, can be obtained in Sicily by amplifying $K_{e s}$, estimated by eq.(8) by a factor of 1.186 . In other words, the following equation can be used to estimate the soil erodibility factor using only soil textural data:

$$
K_{e s}=7.76 \cdot 10^{-6} M^{1.029}
$$

where $K_{e s}$ is expressed in the SI units.

For the two considered data sets (Sicily and Imera Meridionale basin), the NSEI values obtained by eq.(9) were only slightly higher than the corresponding ones obtained by eq.(1).

Eq.(9) is also characterized by a $S S E$ value slightly less than the one corresponding to eq.(1) (Table 3).

This result suggested that eq.(9) does not improve appreciably the quality of the prediction of $K$ as compared to other existing relationships.

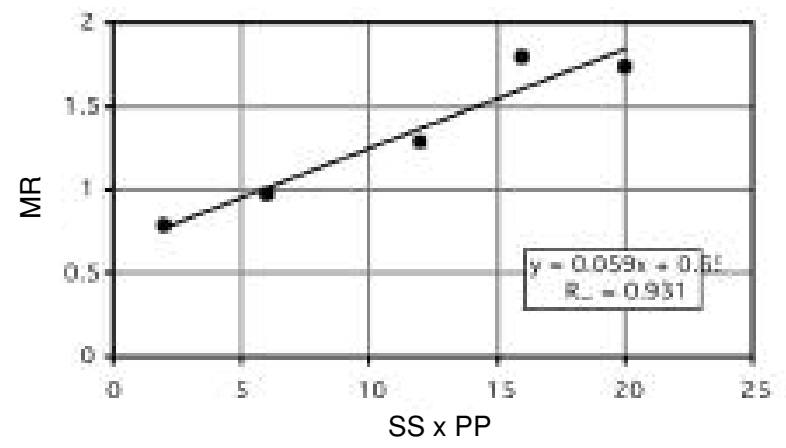

Fig. 10- Relationship between $M R$ (mean of the values corresponding to a given value of the product $S S x P P$ ) and $S S x P P$
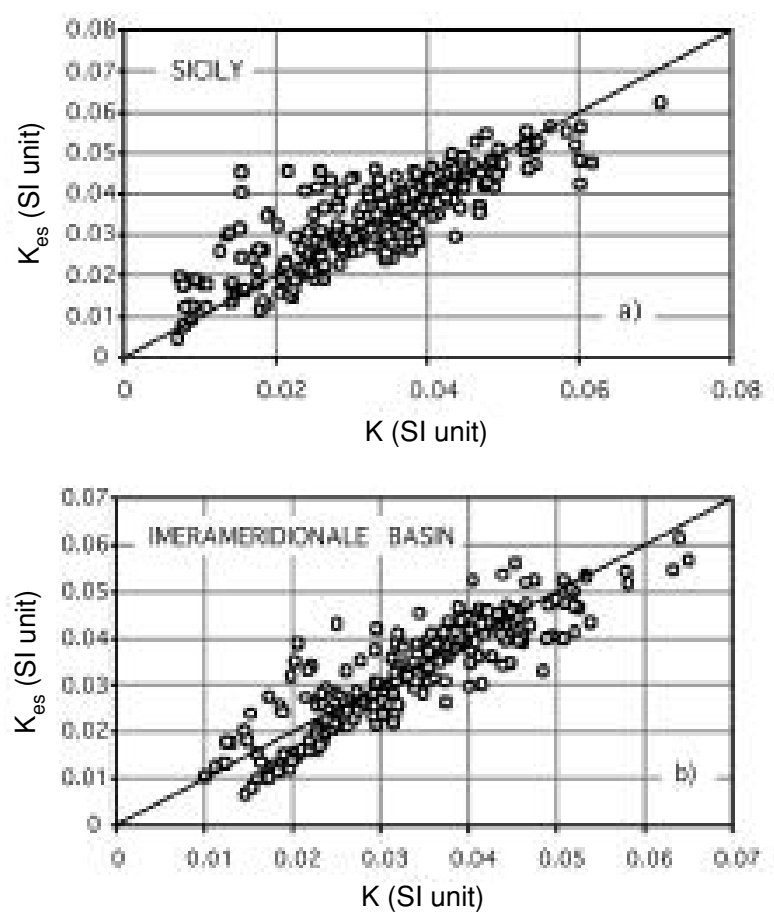

Fig. 11 - Comparison between the soil erodibility factor estimated by eq.(11) and the corresponding values, $K$, obtained by the nomograph for a) the Sicily data set and b) the Imera Meridionale basin data set.
The ratios $K / K_{e s}$, with $K_{e s}^{\prime}$ estimated by eq.(8), were grouped according to the value of the $S S \times P P$ index and a mean ratio of $K / K_{e s}$, denoted by the symbol $M R$, was calculated for each $S S \times P P$ value. Plotting $M R$ against $S S \times P P$ showed that the two variables may be related by the following linear relationship (Fig. 10):

$$
M R=0.655+0.059(S S \times P P)
$$

which is characterized by a value of $r^{2}=0.931$. Therefore, the following relationship was obtained by combining eqs.(8) and (10):

$$
K_{e s}=6.54 \cdot 10^{-6} M^{1.029}[0.655+0.059(S S \times P P)]
$$

Fig. 11 shows the comparison between $K$ and $K_{e s}$, with $K_{e s}$ calculated by eq.(11), for both the calibration (full Sicily) and the validation (Imera Meridionale basin) data sets.

The associated NSEI and SSE values are reported in Table 3.

For both data sets, the performance of eq.(11) $(N S E I>0.67$ and SSE < 0.0118) was appreciably better than the ones of the other tested or developed relationships. Therefore, an estimate of $K$ on the basis of the measured soil particle distribution can be obtained in Sicily using eq.(11).

\section{Conclusions}

The soil erodibility factor of the USLE is a simple descriptor of the soil susceptibility to rill and interrill erosion. In this investigation, a regional analysis was carried out for Sicily using the soil erodibility factors determined by the original nomograph at 471 sampling points.

The relationships proposed by Römkens [1986; 1997] and used in the RUSLE were initially tested. Then, two PTFs for estimating $K$ ' and $K$, respectively, on the basis of the measured PSD were derived. Testing analysis showed that the $K$ estimate by the proposed PTF (eq.11) is appreciably more accurate than the one obtainable by other relationships.

\section{Acknowledgements}

All Authors analyzed the results and contribute to write the paper.

The research was supported by a grant of Progetto FEROS, Assessorato Agricoltura e Foreste, Regione Siciliana.

\section{References}

Bagarello V., Di Stefano C., Lo Piccolo G., Ntamavukiro A., Provenzano G., Schillaci P., Tudisca S. Agro-meteorological characteristics and soil properties in the Ruyigi 
area, Burundi. Edizioni Fotograf, Palermo, 2007, ISBN 978-88-95272-23-8, 97 pp.

Bagarello V., Di Piazza G.V., Ferro V.. Giordano G. Predicting unit plot soil loss in Sicily, south Italy. Hydrological Processes, 2008, 22, 586-595, doi: 10.1002/hyp.6621.

Carsel R.F., Parrish R.S. Developing joint probability distributions of soil water retention characteristics. Water Resources Research, 1988, 24, 755-769.

Ferro V. La sistemazione dei bacini idrografici. McGrawHill, Milano, 2006, 2nd ed., 848 pp. (in Italian), ISBN 88-386-6327-0.

Ferro V. Atlante della qualità dei suoli del bacino del fiume Imera Meridionale. Edizioni Fotograf, Palermo, 2008, 300 pp. (in Italian), ISBN 978-88-95272-56-6.

Gee G.W., Bauder J.W. Particle-size analysis. In: Klute A., Ed. Methods of soil analysis. Part 1, 2nd ed. Madison, WI: ASA and SSSA, 1986, 383-411.

Giordano G., Ferro V., Bagarello V., Di Stefano C., Iovino M., Minacapilli M. Studi applicativi per la realizzazione della carta dell'erosione potenziale del territorio siciliano e del relativo sistema informativo territoriale. Edizioni Anteprima s.r.l., Palermo, 2004, 71 pp.

Nash J.E., Suttcliffe J.E. River flow forecasting through conceptual models, part $1-$ a discussion of principles. Journal of Hydrology, 1970, 10(3), 282-290.

Renard K.G., Foster G.R., Weesies G.A., McCool D.K.,Yoder D.C. Predicting soil erosion by water: a guide to conservation planning with the Revised Universal Soil Loss Equation (RUSLE). USDA Agriculture Handbook No.703, 1997.

Römkens M.J.M., The soil erodibility factor: a perspective. In: El-Swaify S.A., Moldenhauer W.C., Lo A. eds., Soil Erosion and Conservation, Soil Conservation Soc. Am., Ankeny, USA, 1985, 445-461.

Römkens M.J.M., Prasad S.N. and Poesen J.W.A. 1986. Soil erodibility and properties. In Proceedings of the 13th Congress of the International Soil Science Society, 5, 1986, 492-504.

Römkens M.J.M., Young R.A., Poesen J.W.A., McCool D.K., El-Swaify S.A., Bradford J.M. Soil erodibility factor (K). In Renard K.G. et al., Predicting soil erosion by water: a guide to conservation planning with the Revised Universal Soil Loss Equation (RUSLE). USDA Agriculture Handbook No.703, 1997, 65-99.

Salvador Sanchis M.P., Torri D., Borselli L., Poesen J. Climate effects on soil erodibility. Earth Surface Processes and Landforms, 2008, 33, 1082-1097, doi: 10.1002/esp.1604.

Scheinost A.C., Sinowski W., Auerswals K. Regionalization of soil water retention curves in a highly variable soilscape, I. Developing a new pedotransfer function. Geoderma, 1997, 78,129-143.

Shirazi M.A., Boersma L.A unifying quantitative analysis of soil texture. Soil Science Society of America Journal, 1984, 48, 142-147.
Verstraeten G., Van Ost K., Van Rompaey A., Poesen J., Govers G. Evaluating an integrated approach to catchment management to reduce soil loss and sediment pollution trough modelling. Soil Use and Management, 2002, 19, 386-394.

Wischmeier W.H., Smith D.D. Predicting rainfall erosion losses. A guide to conservation planning. USDA Agriculture Handbook No.282, 1978.

Wischmeier W.H., Johnson C.B., Cross B.V., A soil erodibility nomograph for farmland and construction sites. Journal of Soil and Water Conservation, 1971, 26, 189193.

Zacharias S., Wessolek G. Excluding organic matter content from pedotransfer predictors of soil water retention. Soil Science Society of America Journal, 2007, 71,43-50.

\section{SUMMARY}

The soil erodibility factor, $K$, of the Universal Soil Loss Equation (USLE) is a simple descriptor of the soil susceptibility to rill and interrill erosion. The original procedure for determining $K$ needs a knowledge of soil particle size distribution (PSD), soil organic matter, $O M$, content, and soil structure and permeability characteristics. However, $O M$ data are often missing and soil structure and permeability are not easily evaluated in regional analyses. The objective of this investigation was to develop a pedotransfer function (PTF) for estimating the $K$ factor of the USLE in Sicily (south Italy) using only soil textural data. The nomograph soil erodibility factor and its associated first approximation, $K^{\prime}$, were determined at 471 sampling points distributed throughout the island of Sicily. Two existing relationships for estimating $K$ on the basis of the measured geometric mean particle diameter were initially tested. Then, two alternative PTFs for estimating $K^{\prime}$ and $K$, respectively, on the basis of the measured PSD were derived. Testing analysis showed that the $K$ estimate by the proposed PTF (eq.11), which was characterized by a Nash-Suttcliffe efficiency index, NSEI, varying between 0.68 and 0.76 , depending on the considered data set, was appreciably more accurate than the one obtained by other existing equations, yielding NSEI values varying between 0.21 and 0.32 .

Keywords: Soil erosion, Soil erodibility, Pedotransfer functions. 
002_Bagarello(544)_07 18-11-2009 11:46 Pagina 14

$\varnothing$ 